\title{
Erratum to: Up-Regulation of miR-21 Expression Predicate Advanced Clinicopathological Features and Poor Prognosis in Patients with Non-Small Cell Lung Cancer
}

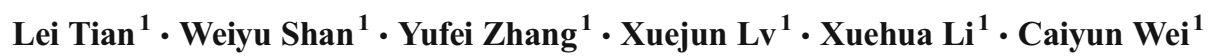

Published online: 27 November 2015

(C) Arányi Lajos Foundation 2015

Erratum to: Pathol. Oncol. Res.

DOI 10.1007/s12253-015-9979-7

The original article contained an error.

The name of the third author should have been Yufei Zhang not Yufei Zhnag.

The corrected author name is shown above.

The online version of the original article can be found at http://dx.doi.org/ 10.1007/s12253-015-9979-7.

\footnotetext{
Lei Tian

drtianlei@163.com

1 Department of Pulmonary Medicine, No. 88 Hospital of PLA, Taian, Shandong Province, People's Republic of China
} 